\title{
Considering the Embryopathogenesis of VACTERL Association
}

\author{
R.E. Stevenson A.G.W. Hunter \\ Greenwood Genetic Center, Greenwood, S.C., USA
}

\author{
Key Words \\ Embryology - Embryopathogenesis - Environmental \\ influences · Genetics · Malformations · VACTERL \\ association
}

\begin{abstract}
The nonrandom co-occurrence of vertebral, anorectal, cardiac, tracheoesophageal, genitourinary, and limb malformations, recognized as the VACTERL association, has not been satisfactorily explained from either a causation or embryopathogenesis standpoint. Few familial cases have been identified and maternal diabetes is the only environmental influence implicated to date. Mutations in single genes have been found in a number of syndromes with one or more of the VACTERL malformations, but these syndromes usually have other features which distinguish them from the VACTERL association. Animal models have provided clues to molecular pathways that may be involved in the embryogenesis of the VACTERL structures. What is lacking is the systematic study of individual genes and pathways in well-composed cohorts of patients, which is now possible with high throughput molecular technologies.
\end{abstract}

Copyright $\odot 2013$ S. Karger AG, Basel

Development of a unifying embryopathogenesis that encompasses the major malformations of the VACTERL association (vertebral defects, anorectal malformations, cardiac defects, tracheoesophageal fistula, renal anoma- lies, and limb abnormalities) faces significant challenges. The malformations affect 5 different anatomical systems - skeletal, gastrointestinal, respiratory, cardiac and genitourinary. Some are axial, others appendicular. Some of the malformations make their appearance early in the embryological period, 23-30 days post conception, while others occur later in embryogenesis.

These challenges to a unifying embryopathogenesis notwithstanding, a number of potential explanations should be considered in seeking to understand why or how these malformations co-occur in nonrandom fashion. Among potential explanations are: (1) teratogenic influence(s) that are chronic throughout the period of embryogenesis, (2) an inaugural malformation that secondarily disturbs development of other anatomical structures, the so-called malformation sequence or cascade, (3) disturbances of molecular pathways or mutations of single genes that are critical in formation of the multiple anatomic systems affected, and (4) disturbances in a developmental process that is essential to all systems affected.

\section{The Timing and Embryological Processes Involved in the VACTERL Malformations}

The malformations in the VACTERL association develop at different stages of embryogenesis (fig. 1) [O'Rahilly and Müller, 2001; Sadler, 2012]. The anatomical structures involved are uniformly absent prior to 23 days post

\section{KARGER \\ Fax +4161306 1234}

E-Mail karger@karger.com

www.karger.com
(C) 2013 S. Karger AG, Basel

1661-8769/13/0042-0007\$38.00/0

Accessible online at:

www.karger.com/msy
Roger E. Stevenson, MD

Greenwood Genetic Center

113 Gregor Mendel Circle

Greenwood, SC 29646 (USA)

E-Mail res@ggc.org 


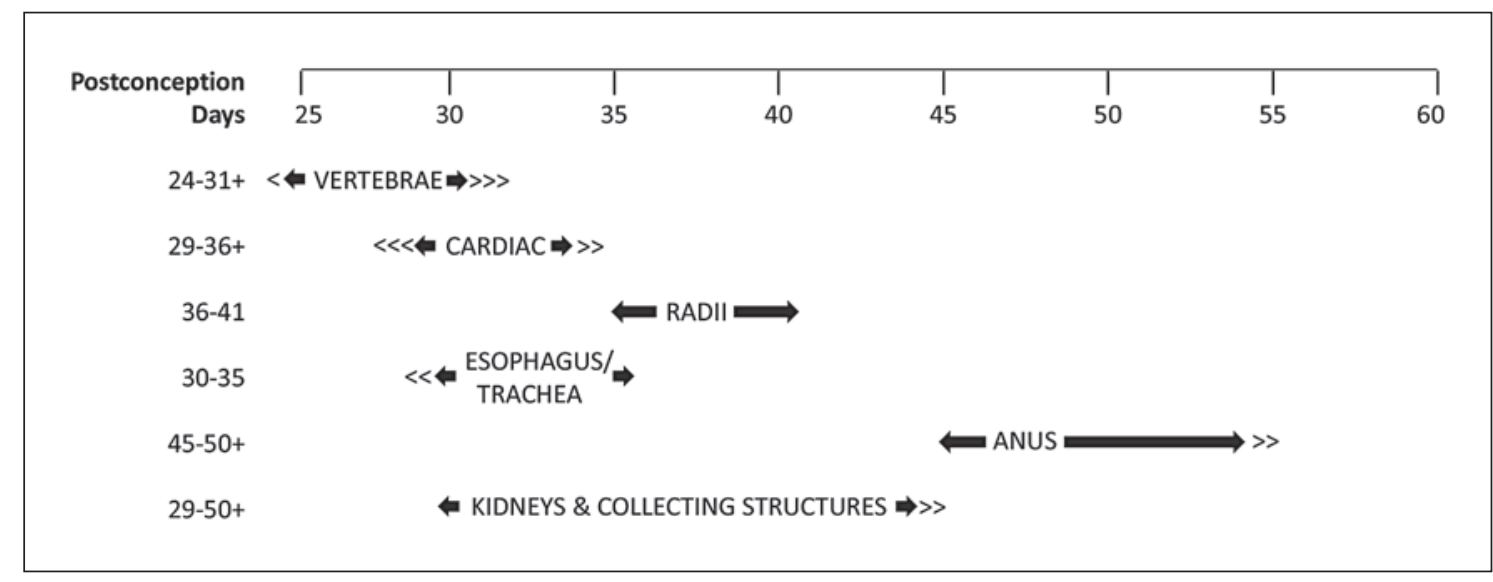

Fig. 1. Approximate days post conception during which anatomic structures in VACTERL association are formed. Genetic or environmental influences that affect the anlage of these structures may occur earlier than the days indicated.

conception and are more or less fully formed by 56 days post conception. The vertebrae, especially the thoracic vertebrae that are most often affected, are formed earliest in this embryological window (23-32 days), anorectal structures latest (45-56 days and beyond), and the heart, tracheoesophageal structures, and forearm bones in between (29-41 days). That disturbances may occur in processes that are active prior to the visible embryogenesis of an organ must also be considered.

It appears that multiple embryological processes are disturbed in the genesis of the VACTERL malformations. Abnormal or asymmetric timing of a molecular oscillator termed the segmentation clock has been shown to result in malsegmentation of the vertebrae [Pourquié and $\mathrm{Ku}$ sumi, 2001; Oates et al., 2012]. Mesodermal proliferation and migration, epithelial-mesenchymal interactions and programmed cell death are involved in atresias of the esophagus and anus and in separation of the trachea and esophagus [Bergmann et al., 2003; Sadler, 2012]. Failure to lay down, condense or chondrify the anlage of the radius is involved in radial aplasia. Renal agenesis could result from failure, early in the 5th week, of the ureteric bud to develop appropriately or because of primary failure of the metanephric mesenchyme. Lower urinary defects involve abnormal development of the mesonephros/mesonephric duct. The common cardiac anomalies in VACTERL association - ventricular and atrial septal defects and Tetralogy of Fallot - share abnormal development of the cardiac septi, and they show clustering when there is intrafamilial recurrence [Fraser and Hunter, 1975].

\section{Environmental Influences and VACTERL Association}

Chronic exposure during the first trimester to environmental agents is a plausible explanation for the induction of malformations that make their appearance at different embryological times. Thalidomide exposure in early gestation affected multiple anatomical systems and offers the most dramatic and perhaps most relevant example. Although limb anomalies were the sentinel malformations of thalidomide exposure, craniofacial, cardiac, and gastrointestinal structures were also affected depending on the time of exposure [Knapp et al., 1962; Quibell, 1981; Lenz, 1988]. Midline vascular malformations of the face were present in most affected infants, malformations of the ears in $20 \%$, cardiac malformations in $10 \%$, and atresias or stenoses of the gastrointestinal system in less than 10\% [Taussig, 1962; Quibell, 1981].

The evidence for an environmental influence that could account for a significant percentage of VACTERL association cases is quite meager. However, certain VACTERL malformations, particularly vertebral, cardiac and limb malformations, have been commonly found in infants of mothers with diabetes mellitus [Pedersen et al., 1964; Mills, 1986; Becerra et al., 1990; Janssen et al., 1996]. The mechanism by which maternal diabetes predisposes to malformations appears complex, involving hyperglycemia, oxidative stress, mitochondrial dysfunction, and disturbance of certain key developmental pathways [Reece, 2012]. Although some infants meeting VACTERL association criteria have been born of mothers with maternal diabetes, this is not the case for most affected in- 
fants [Ewart-Toland et al., 2000; Stevenson, unpubl. observations].

Among the chemical teratogens, adriamycin, an antibiotic cancer agent, can produce malformations in rats very similar to those of the VACTERL association [Beasley et al., 2000]. Most rat embryos exposed to adriamycin between gestation days 6 and 9 develop esophageal atresia (EA) with or without tracheoesophageal fistula (TEF), vertebral malsegmentation defects and cardiovascular anomalies, predominantly those involving conotruncal separation [Diez Pardo et al., 1996; Kotsios et al., 1998]. The upper limbs are more commonly malformed than the lower, but in a less severe and less specific way than in VACTERL association [Abu-Hijleh et al., 2000]. Anorectal and genitourinary malformations have not been reported in this model [Beasley et al., 2000]. Clues from the adriamycin rat model suggest that failure of the notochord to regionally organize the axial structures and failure of programmed cell death (apoptosis) to correctly separate and/or connect developing structures may be key processes in the induced embryopathology.

Gestational exposure to certain other drugs and chemicals (anticonvulsants, folic acid antagonists, alcohol) has also been linked to one or more of the VACTERL malformations, but none has been implicated in the full group of major VACTERL malformations [Milunsky et al., 1968; Shaw and Steinbach, 1968; Hanson and Smith, 1975; Hanson et al., 1976].

\section{Malformation Sequences and VACTERL Association}

David Smith, the founder of dysmorphology, proposed the concept of malformation sequence to encompass an inaugural malformation and the secondary consequences of that malformation [Smith, 1982]. 'Potter Sequence' was used to describe the secondary signs including oligohydramnios, pulmonary immaturity, and deformation of facial structures and limbs that result from renal agenesis. 'Pierre Robin Sequence' was used to describe micrognathia/retrognathia and the associated secondary glossoptosis and cleft palate. Although no such sequence has been proposed for VACTERL association, one might speculate that such a sequence could be initiated by vertebral malsegmentation with secondary malformative consequences on adjacent (tracheoesophageal, cardiac, and renal) structures and remote (limb and anal) structures. The secondary consequences might involve vascular disturbance(s) as an intermediary phenomenon (see below). The hint of a scenario such as this could be taken from the adriamycin-induced rat model of VACTERL association in which maldevelopment of the notochord might be the initiating embryological disturbance [Beasley et al., 2000].

\section{Single Gene Mutations among Conditions with Component Malformations Present in VACTERL Association}

Few instances of first degree relatives with 3 or more VACTERL malformations have been identified [Nezerati and McLeod, 1999; Solomon et al., 2010b; Hilger et al., 2012]. In none of these families was a specific causative factor - genetic or environmental - found. This is in contrast with VACTERL-hydrocephalus in which numerous familial cases, with apparently both X-linked and autosomal patterns of inheritance, are reported [Hunter and MacMurray, 1987; Evans et al., 1989; Genuardi et al., 1993; Froster et al., 1996; Lomas et al., 1998]. FANCB mutations have been found in a minority of the X-linked cases [Holden et al., 2006; McCauley et al., 2011].

Each of the major malformations in VACTERL association occurs as an isolated anomaly and as a component of a number of malformation syndromes (fig. 2). Mutations in single genes have been identified in many of these syndromes, but it is the exception for all of the major VACTERL malformations to occur in any of these syndromes that generally also include malformations that are not seen in VACTERL association. One exception is the report of a missense mutation in ZIC3, an X-linked gene associated with heterotaxy, in a patient who had all of the VACTERL malformations and whose cousin and a nephew had cardiovascular anomalies [Ware et al., 2004]. ZIC3 deletion or mutation has been reported in 2 other males who met criteria for VACTERL association [Wessels et al., 2010; Chung et al., 2011].

Limb anomalies, most often radial ray defects, occur in about half of patients diagnosed with VACTERL association [Weaver et al., 1986; Botto et al., 1997; Solomon et al., 2010a]. Syndromes with radial ray defects include those caused by mutations in TBX5 (Holt-Oram syndrome), RECQL4 (Baller-Gerold syndrome), SALL1 (Townes-Brocks syndrome), and several FANC genes (Fanconi anemia). Each of these syndromes includes one or more additional VACTERL malformation(s).

Tracheoesophageal anomalies are sentinel features of VACTERL association, occurring in over half of patients so diagnosed. The current knowledge of the genes involved in tracheoesophageal development was recently 


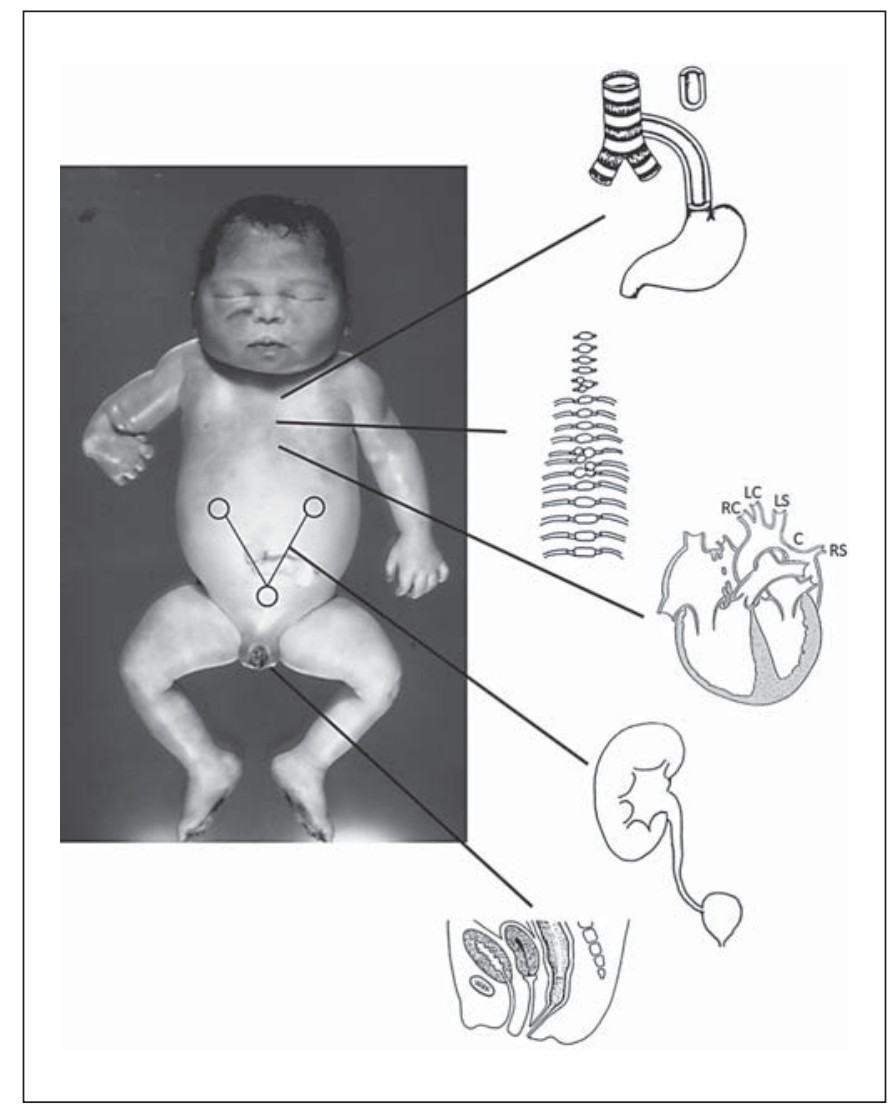

Fig. 2. Thirty-four week female fetus with VACTERL association: 14 thoracic vertebrae and ribs with multiple vertebral segmentation defects at C6-7, T5-6, and T6-7; ectopic hypoplastic anus at base of vagina; cardiomegaly with 2 atrial septal defects, a preductal coarctation (C) and aberrant major branches of aorta in order of right carotid (RC), left carotid (LC), left subclavian (LS), and right subclavian (RS) which coursed behind the esophagus and trachea; tracheoesophageal fistula and esophageal atresia; left renal agenesis and right hydronephrosis; and right radial aplasia with hypoplastic thumb.

reviewed by Faure and De Santa Barbara [2011]. Segmentation of the gut into different regions is controlled by the Hox genes with Hoxa 3 and Hoxb 4 being expressed in the foregut endoderm. Shh is expressed throughout the gut endoderm but has a specific expression pattern during tracheoesophageal development with earlier expression and patterning in the ventral foregut and a temporary inhibition of its expression in tracheal endoderm. Sox 2 is also expressed in the foregut, and the transcription factor $N k x 2$ is specifically expressed in the endoderm of the developing trachea but not in the esophagus. Lack of $N k x 2$ or Shh expression leads to failure of separation of the trachea from the esophagus. Endodermal cells secrete $\mathrm{SHH}$ that binds to and activates Patched in the associated mesenchymal cells. Activated PTCH1 in turn causes activation of GLI1/2, which has effects on various mesenchymespecific genes including Ptch1, Gli1 and Bmp4, the latter of which is only expressed in the ventral foregut. Condensation of mesenchyme at the site of tracheoesophageal separation is noted and may be vital to that process. Syndromes in which TEF and/or EA occur, at least in a minority of cases, include Hypertelorism-hypospadias syndrome (MID1 mutations), CHARGE syndrome (CHD7 mutations) and VACTERL-hydrocephalus syndrome (FANCB mutations). TEF and the other major VACTERL anomalies were reported in a patient with a mutation in ZIC3 by Ware et al. [2004]. Wessels et al. [2010] described a patient with anal atresia, laryngoesophageal and tracheoesophageal atresia, cardiac dextroposition with persistent left superior vena cava, and unilateral multicystic kidney who also had a ZIC3 mutation. Chung et al. [2011] described a family in which an Xq26.3 deletion including the ZIC3 gene segregated. One male met VACTERL-H criteria with imperforate anus, duplication of the descending colon, multiple cardiovascular anomalies, dysraphic spine with L3-4 block vertebra, fused kidneys, and hydrocephalus due to aqueductal stenosis. Two maternal male relatives with the deletion had imperforate anus and one maternal nephew (fetus) had heterotaxy, cardiovascular malformations and imperforate anus. Reardon et al. [2001] found a heterozygous missense mutation in $P T E N$ in a male with TEF, macrocephaly, mild radial ray deficiency, and 'fullness of the ventricles', features they considered to resemble the VACTERL association. Arrington et al. [2010] proposed $L P P$ as a candidate gene for EA/TEF/VACTERL. They reported a patient with EA/ TEF that met VATER criteria and was deleted for only LPP. However, a screen of 195 patients with EA/TEF/ VACTERL (70 with VACTERL) found no copy number variations or loss of heterozygosity [Hernández-García et al., 2012].

Multiple vertebral anomalies, usually in the form of hemivertebrae, fusions, extra or missing vertebrae and rib defects occur in most patients diagnosed with VACTERL association. Among other malformation syndromes with high rates of vertebral malformations are Alagille, spondylocostal dysplasia and Okihiro. Mutations in genes in the Notch signaling pathway (JAG1 and $D L L 3)$ have been identified in Alagille syndrome and spondylocostal dysplasia and mutations in SALL4 in Okihiro syndrome. NOTCH has a pivotal role in the coordination of gene expression in contiguous cells and hence the development of the somite segmentation clock [Lew- 
is et al., 2009]. A signaling cell secretes a ligand, such as Jagged, that binds to the NOTCH receptor of the contiguous receiving cell, which results in NOTCH cleavage and release of its intracellular component which targets, among other genes, the Hes family. Interaction with the Hes pathway has been a suggested site of interaction with the FANCB gene in VACTERL-H (see below).

Cardiac malformations occur in over three-fourths of patients with VACTERL association [Solomon et al., 2010a]. Malformations with functional significance probably account for only half of this number. Numerous malformation syndromes that include cardiac defects are due to single gene mutations: Alagille, CHARGE, Feingold, Holt-Oram syndrome, Hypertelorism-hypospadias, Townes-Brocks, and VACTERL-hydrocephalus syndromes. In each, at least one other VACTERL malformation is usually present.

Imperforate anus occurs in about half of patients with VACTERL association. A spectrum of anorectal anomalies have been reported including fistulas into the genitourinary system and other genitourinary anomalies. Anal anomalies occur in several syndromes known to have single gene causation: Townes-Brocks (SALL1), PallisterHall (GLI3), Hypertelorism-hypospadias (MID1) and Currarino syndromes (HLXB9 mutations).

Genitourinary anomalies in the form of horseshoe kidney, renal cysts, renal dysplasia, and renal agenesis with or without associated anomalies of the collecting structures or genitals occur in over half of patients. These malformations often exist in a subclinical state and rarely lead to organ failure. Genitourinary anomalies are commonly seen in a number of conditions which have other malformations of VACTERL association (CHARGE, Alagille, Feingold, Fryns, Pallister-Hall, Townes-Brocks, Smith-Lemli-Opitz, Okihiro, and other syndromes).

VACTERL-hydrocephalus is the only single gene disorder that encompasses all the VACTERL acronym malformations. This serious condition almost always results in early lethality. Hydrocephalus, the feature that distinguishes the condition from the sporadic VACTERL association, is due to aqueductal stenosis. Mutations in FANCB have been found in a minority of cases [Holden et al., 2006; McCauley et al., 2011].

Szumska et al. [2008] noted that a mutation in Pcsk5 in the mouse produced VACTERL-caudal regressionCurrarino syndrome-like malformations. They screened 36 patients with VACTERL and 13 with caudal regression and found non-synonymous variants that were not observed in ethnically matched controls in 4 of the former and 1 of the latter patients. The mouse mutant was shown to cause abnormal expression of several Hox genes and $M n x 1$ (Hlxb9). The latter gene is a principal gene responsible for familial Currarino syndrome [Kim et al., 2007].

\section{Molecular Pathways Involved in Formation of Anatomical Structures Affected in VACTERL Association}

A number of signaling pathways are involved in the formation of the diverse anatomical structures affected in VACTERL association. Prominent among these are the Sonic hedgehog ( $\mathrm{SHH}$ ) pathway, known to be involved in brain, limb, and spine formation; the Notch (NOTCH) pathway, known to be involved in cardiovascular and spine formation; and the fibroblast growth factor (FGF) pathway, known to be involved in limb, vasculature, and spine formation.

Although argument has been made for disturbance of the SHH pathway as a cause for VACTERL association, no specific mutations in $S H H$ or the closely related GLI genes have been found in patients with VACTERL association [Garcia-Barceló et al., 2008a; Aguinaga et al., 2010]. Mutations in Shh, Gli2, and Gli3 have produced VACTERL malformations in mice [Kim et al., 2001]. Mutations in HOXD13 and FOXF1, two genes linked to the SHH pathway, have been described in patients with VACTERL or VACTERLlike presentations [Garcia-Barceló et al., 2008b; Agochukwu et al., 2011]. However, the SHH pathway is complex with additional participants that may have potential to be involved in VACTERL association. These might include the mammalian equivalents of the activator Smoothened (Smo), the G-protein coupled receptor, and the cytoplasmic signaling components Cos2, Fused (Fu) and Suppressor of Fused (Sufu) [Varjosalo and Taipale, 2008].

The NOTCH pathway is an intercellular signaling complex involved in embryonic development of heart, vasculature, hematopoietic system, vertebrae and ribs, and other organs. The NOTCH receptors (NOTCH1-4) and other components of this pathway, including the membrane bound ligands JAG1, JAG2, DLL1, DLL2, and DLL3, influence various cellular processes including proliferation and apoptosis. Gametic mutations are not known for NOTCH1, 2 and 4, whereas those in NOTCH3 cause CADASIL. Certain cardiac and vascular malformations and malsegmentation of the vertebrae are among the consequences of faulty $\mathrm{NOTCH}$ signaling; Alagille in the case of JAG1 and spondylocostal dysplasia in the case of DLL3 [High and Epstein, 2008]. The signaling pathway 
includes the processing and subsequent cleavage and heterodimerization of extracellular, transmembrane and intracellular NOTCH components by the endoplasmic reticulum and Golgi [Kopan and Ilagan, 2009]. The heterodimer is moved to the cell membrane where it binds the JAG and DLL ligands resulting in cleavage from the NOTCH extracellular domain by TACE (ADAM metalloprotease TNF- $\alpha$ converting enzyme). The transmembrane and intracellular domains are split by $\gamma$-secretase and the NOTCH intracellular domain is moved to the nucleus where it becomes associated with the CSL family transcription complex with resulting activation of target genes including $M y c, p 21$ and the Hes family. Thus, the NOTCH signaling pathway includes a number of potential areas for exploration with respect to the causation of VACTERL association.

The FGF signaling pathway involves the various fibroblast growth factors, their receptors and other components that during embryogenesis stimulate angiogenesis, and influence neurogenesis, skeletal development, tracheal branching, and many other developmental processes. Mutations in the FGFs and FGFRs have not been implicated in specific VACTERL malformations, but mutations in the FGFRs have caused generalized skeletal dysplasias and craniosynostosis. Early in bone development, FGFs stimulate cell proliferation, while in more mature cells they promote apoptosis [Mansukhani et al., 2000]. Although disturbances in these cellular processes might play a role in VACTERL association, this pathway does not appear as a prime candidate to explain the association.

\section{Disturbance in a Developmental Process and VACTERL Association}

A number of developmental processes are involved in formation of all anatomical systems affected in the VACTERL association. Mesoderm production is an early and essential component of all anatomical structures. Adequate mesoderm production must occur via migration and transformation of precursor ectoderm through the primitive streak, proliferation, and distribution to all sites of embryogenesis. Disturbance of this fundamental embryological process plausibly might disrupt development globally, leading to embryonic death or locally producing faulty formation of individual anatomical structures. In their initial description of the VATER association, Quan and Smith [1973] suggested that a defect in mesoderm prior to day 35 post conception could result in all of the component malformations. Others have also supported the concept that failure of normal mesoderm migration during the first 4 weeks of embryogenesis could be the initiating pathogenic event [Martinez-Frias and Frias, 1999; Bergmann et al., 2003]. A closely related developmental process is signaling between ectoderm and mesoderm, the so-called epithelial-mesenchymal interactions, which appears to be essential to the correct formation of most anatomical structures.

A later, but equally ubiquitous, developmental process essential to all anatomical structures is vascular supply. Adequate oxygen and nutrient supplies may be interrupted locally by faulty development of blood vessels and by hemorrhage or thrombosis. A vascular embryopathogenesis has been posited to account for most of the individual VACTERL malformations. Absence of the inferior mesenteric artery has been noted in association with anal atresia [Stevenson et al., 1986], disturbed formation of the intersegmental arteries has been observed with malsegmentation of the vertebrae [Müller et al., 1986; Stevenson et al., 1987] and absence of the radial artery recorded in radial aplasia [Duncan and Shapiro, 1993]. The presence of a single umbilical artery in a minority of infants with VACTERL association further invites the question of whether vascular pathology contributes to the co-occurrence of the VACTERL malformations [Quan and Smith, 1973; Auchterlonie and White, 1982; Weaver at al., 1986; Duncan and Shapiro, 1993; Shaw-Smith, 2010; Stevenson, unpubl. observations]. However, the major and unresolved criticism of the vascular hypothesis is whether the vascular changes observed cause malformations or are effects of malformations [Sadler and Rasmussen, 2010]. There may be some reason to suggest that primary thrombosis/hemorrhage is an unlikely explanation for VACTERL. For one there is a strong propensity for upper limb involvement and there is no obvious vascular basis for that observation. In addition, the limb defects in VACTERL tend to differ from those more often ascribed (without proof) to such thrombo-hemorrhagic events where there are generally terminal deficiencies with or without hypoplastic digits and nails.

However, there is some evidence in support of a more primary vascular pathogenesis for some VACTERL anomalies. Retinoic acid exposure of Syrian hamsters resulted, within 24 hours, in caudal vessel changes and dissection of the aortic contents into the adjacent unsegmented mesoderm [Wiley, 1983]. This was associated with neural tube and notochordal anomalies, and loss of intercellular relationships in the paraxial mesoderm. By 36 hours there were abnormalities in the appearance of 
the caudal somites, and in later studied embryos there were defects in the sclerotomes and the vertebrae. There are experimental data implicating hypoxia as a teratogen [Chernoff and Rogers, 2010]. An early example is in rabbits exposed to hypoxia at human equivalent 23-30 days gestation that resulted in sagittal cleft vertebrae [Degenhardt and Knoche, 1959]. The notochord appeared to be the primary site of damage, resulting in faulty induction of the adjacent paraxial mesoderm. Embryos allowed to continue showed vertebral anomalies.

\section{Discussion}

In the 4 decades since the initial description and revisions of the VACTERL association, a vast number of diverse studies have been conducted on this malformation complex. Yet, this large body of clinical and epidemiological observations, animal experimentation, and molecular probing has not yielded a clear and unifying embryopathogenesis. A confounding feature of the VACTERL association that must be taken into account is that the embryologic timing differs between the component malformations.

A key characteristic of teratogenic influences that may bring together seemingly unrelated malformations is that chronic or repetitive exposure of the developing anatomy to an environmental or genetic influence may permit multiple organ systems to be affected even though they are on different developmental schedules. Environmental influences that might be active throughout the embryological period include exposure to teratogenic drugs or a maternal metabolic disturbance. In similar fashion, the effects of a single gene mutation might extend throughout the period of embryogenesis. In the decades of experience with the VACTERL association, no potential teratogen, pregnancy characteristic, or genetic alteration common to the majority or even a substantial minority of cases, has been identified.

Anatomically disparate anomalies may also follow a single early embryonic progenitor event that predestines disturbances in derivative cell populations. Since the VACTERL association was first recognized, there have been suggestions that such an early event that disturbs mesodermal migration, proliferation, differentiation and/or apoptosis could account for the component malformations. No specific observations in humans support this concept. However, the abnormal shape and positioning of the notochord and the abnormal timing and location of apoptosis in the foregut and hindgut in the adria- mycin-induced rat model hint at an earlier progenitor defect [Beasley et al., 2000]. Clarification of this potential pathogenetic basis for the VACTERL malformation will depend on the further study of early embryogenesis possible only in animal models.

Mutations in certain individual genes have produced multiple malformation syndromes with some phenotypic overlap with VACTERL association [Shaw-Smith, 2010]. Mutations in NMYC, GLI3, CHD7, and SALL1 cause Feingold, Pallister-Hall, CHARGE, and TownesBrocks syndromes, respectively, each of which may exhibit 2 or more of the VACTERL malformations, but which generally have other distinctive findings that allow clinical differentiation. This is also the case for autosomal recessive Fanconi anemia, which may be caused by mutations in one of several FANC genes, with about $5 \%$ of patients meeting VACTERL association criteria.

Among patients with the full composite of major VACTERL malformations, a plausible specific causative factor is rarely identified. The exceptions include some cases associated with maternal diabetes, a few cases with ZIC3 mutation or deletion and the cases of VACTERLhydrocephalus with FANCB mutations [Ewart-Toland et al., 2000; Ware et al., 2004; Holden et al., 2006; McCauley et al., 2011]. Still, the case for causative mutations in a single gene to explain most cases of VACTERL association cannot be considered excluded. Application of current and future molecular technology in the systematic study of well-composed cohorts of patients is necessary to clarify the role of genetic alterations in the causation of this malformation complex.

While causal heterogeneity for VACTERL association has been widely considered as likely, this is by no means certain [Khoury et al., 1983; Botto et al., 1997; ShawSmith, 2006, 2010; Solomon, 2011]. The experience with CHARGE association/syndrome is instructive in this regard. Once considered to be an association, the divergent phenotype of CHARGE syndrome became understandable once the single pleiotropic gene, $C H D 7$, was identified.

\footnotetext{
References Abu-Hijleh G, Qi BQ, Williams AK, Beasley SW: Development of the bones and synovial joints in the rat model of the VATER association. J Orthop Sci 5:390-396 (2000).

-Agochukwu NB, Pineda-Alvarez DE, Keaton AA, Warren-Mora N, Raam MS, et al: Analysis of FOXF1 and the FOX gene cluster in patients with VACTERL association. Eur J Med Genet 54:323-328 (2011).
} 
-Aguinaga M, Zenteno JC, Pérez-Cano H, Morán $\mathrm{V}$ : Sonic hedgehog mutation analysis in patients with VACTERL association. Am J Med Genet A 152A:781-783 (2010).

-Arrington CB, Patel A, Bacino CA, Bowles NE: Haploinsufficiency of the LIM domain containing preferred translocation partner in lipoma (LPP) gene in patients with tetralogy of Fallot and VACTERL association. Am J Med Genet A 152A:2919-2923 (2010).

-Auchterlonie IA, White MP: Recurrence of the VATER association within a sibship. Clin Genet 21:122-124 (1982).

- Beasley SW, Diez Pardo J, Qiu BQ, Tovar JA, Xia HM: The contribution of the adriamycin-induced rat model of the VATER association to our understanding of congenital abnormalities and their embryogenesis. Pediatr Surg Int 16:465-472 (2000).

Becerra JE, Khoury MJ, Cordero JF, Erickson JD: Diabetes mellitus during pregnancy and the risks for specific birth defects: a populationbased case-control study. Pediatrics 85:1-9 (1990).

-Bergmann C, Zerres K, Peschgens T, Senderek J, Hörnchen H, Rudnik-Schöneborn S: Overlap between VACTERL and hemifacial microsomia illustrating a spectrum of malformations seen in axial mesodermal dysplasia complex (AMDC). Am J Med Genet A 121A: 151-155 (2003).

Botto LD, Khoury MJ, Mastroiacovo P, Castilla EE, Moore CA, et al: The spectrum of congenital anomalies of the VATER association: an international study. Am J Med Genet 71: 8-15 (1997).

Chernoff N, Rogers JM: Hypoxia and the edema syndrome: elucidation of a mechanism of teratogenesis. Birth Defects Res B Dev Reprod Toxicol 89:300-303 (2010).

Chung B, Shaffer LG, Keating S, Johnson J, Casey B, Chitayat D: From VACTERL-H to heterotaxy: variable expressivity of ZIC3-related disorders. Am J Med Genet A 155A:11231128 (2011).

Degenhardt KH, Knoche E: Analysis of intrauterine malformations of the vertebral column induced by oxygen deficiency. Can Med Assoc J 60:441-445 (1959).

Diez Pardo JA, Qi B, Navarro C, Tovar JA: A new rodent experimental model of oesophageal atresia and tracheooesophageal fistula: preliminary report. J Pediatr Surg 31:498-502 (1996).

Duncan PA, Shapiro LR: Interrelationships of the hemifacial microsomia-VATER, VATER, and sirenomelia phenotypes. Am J Med Genet 47:75-84 (1993).

-Evans JA, Stranc LC, Kaplan P, Hunter AG: VACTERL with hydrocephalus: further delineation of the syndrome(s). Am J Med Genet 34:177-182 (1989).

Ewart-Toland AM, Yankowitz J, Winder A, Imagire R, Cox VA, et al: Oculoauriculovertebral abnormalities in children of diabetic mothers. Am J Med Genet 90:303-309 (2000).
Faure S, De Santa Barbara P: Molecular embryology of the foregut. J Pediatr Gastroenterol Nutr 52 (Suppl 1):S2-S3 (2011).

- Fraser FC, Hunter AGW: Etiological relationships between categories of congenital heart malformations. Am J Cardiol 36:793-796 (1975).

-Froster UG, Wallner SJ, Reusche E, Schwinger E, Rehder H: VACTERL with hydrocephalus and branchial arch defects: prenatal, clinical, and autopsy findings in two brothers. Am J Med Genet 62:169-172 (1996).

-Garcia-Barceló MM, Chi-Hang Lui V, Miao X, So MT, Yuk-yu Leon T, et al: Mutational analysis of $\mathrm{SHH}$ and GLI3 in anorectal malformations. Birth Defects Res A Clin Mol Teratol 82:644-648 (2008a).

Garcia-Barceló MM, Wong KK, Lui VC, Yuan ZW, So MT, et al: Identification of a HOXD13 mutation in a VACTERL patient. Am J Med Genet A 146A:3181-3185 (2008b).

Genuardi M, Chiurazzi P, Capelli A, Neri G: Xlinked VACTERL with hydrocephalus: the VACTERL-H syndrome. Birth Defects Orig Artic Ser 29:235-241 (1993).

Hanson JW, Smith DW: The fetal hydantoin syndrome. J Pediatr 87:285 (1975).

Hanson JW, Jones KL, Smith DW: Fetal alcohol syndrome: experience with 41 patients. JAMA 235:1458 (1976).

-Hernández-García A, Brosens E, Zaveri HP, de Jong EM, Yu Z, et al: Contribution of LPP copy number and sequence changes to esophageal atresia, tracheoesophageal fistula, and VACTERL association. Am J Med Genet A 158A:1785-1787 (2012).

High FA, Epstein JA: The multifaceted role of Notch in cardiac development and disease. Nat Rev 9:49-61 (2008).

-Hilger A, Schramm C, Draaken M, Mughal SS, Dworschak G, et al: Familial occurrence of the VATER/VACTERL association. Pediatr Surg Int 28:725-729 (2012).

Holden ST, Cox JJ, Kesterton I, Thomas NS, Carr C, Woods CG: Fanconi anaemia complementation group B presenting as $\mathrm{X}$ linked VACTERL with hydrocephalus syndrome. J Med Genet 43:750-754 (2006).

Hunter AGW, MacMurray B: Malformations of the VATER association plus hydrocephalus in a male infant and his maternal uncle. Proc Greenwood Genet Center 6:146-147 (1987).

Janssen PA, Rothman I, Schwartz SM: Congenital malformations in newborns of women with established and gestational diabetes in Washington State, 1984-91. Paediatr Perinat Epidemiol 10:52-63 (1996).

Khoury MJ, Cordero JF, Greenberg F, James LM, Erickson JD: A population study of the VACTERL association: evidence for its etiologic heterogeneity. Pediatrics 71:815-820 (1983).

Kim IS, Oh SY, Choi SJ, Kim JH, Park KH, et al: Clinical and genetic analysis of HLXB9 gene in Korean patients with Currarino syndrome. J Hum Genet 8:698-701 (2007).
Kim JH, Kim PCW, Hui C-C: The VACTERL associations: lessons from the sonic hedgehog pathway. Clin Genet 59:306 (2001).

Knapp K, Lenz W, Nowack E: Multiple congenital abnormalities. Lancet 280:725 (1962).

Kopan R, Ilagan MX: The canonical Notch signaling pathway: unfolding the activation mechanism. Cell 137:216-213 (2009).

Kotsios C, Merei J, Hutson JM, Graham JH: Skeletal anomalies in the adriamycin-exposed prenatal rat: a model for VATER association. J Orthop Res 16:50-53 (1998).

Lenz W: A short history of thalidomide embryopathy. Teratology 38:203-215 (1988).

-Lewis J, Hanisch A, Holder M: Notch signaling, the segmentation clock, and the patterning of vertebrate somites. J Biol 8:44 (2009).

Lomas FE, Dahlstrom JE, Ford JH: VACTERL with hydrocephalus: family with X-linked VACTERL-H. Am J Med Genet 76:74-78 (1998).

Mansukhani A, Bellosta P, Sahni M, Basilico C: Signaling by fibroblast growth factors (FGF) and fibroblast growth factor receptor 2 (FGFR2)-activating mutations blocks mineralization and induces apoptosis in osteoblasts. J Cell Biol 149:1297-1308 (2000).

Martinez-Frias ML, Frias JL: VACTERL as primary, polytopic developmental field defects. Am J Med Genet 83:13-16 (1999).

McCauley J, Masand N, McGowan R, Rajagopalan S, Hunter A, et al: X-linked VACTERL with hydrocephalus syndrome: further delineation of the phenotype caused by FANCB mutations. Am J Med Genet A 155A:23702380 (2011).

Mills JL: Malformations in infants of diabetic mothers, in Sever JL, Brent RL (eds): Teratogen Update: Environmentally Induced Birth Defect Risks, p 165 (A.R. Liss, New York 1986)

Milunsky A, Fraef JW, Gaynor MF: Methotrexate-induced congenital malformations. J Pediatr 72:790 (1968).

Müller F, O’Rahilly R, Benson DR: The early origin of vertebral anomalies, as illustrated by a 'butterfly vertebra'. J Anat 149:157-169 (1986).

Nezerati MM, McLeod DR: VACTERL manifestations in two generations of a family. Am J Med Genet 82:40-42 (1999).

Oates AC, Morelli LG, Ares S: Patterning embryos with oscillations: structure, function and dynamics of the vertebrate segmentation clock. Development 139:625-639 (2012).

O’Rahilly R, Müller F: Human Embryology \& Teratology, ed 3 (Wiley-Liss, New York 2001).

Pedersen LM, Tygstrup I, Pedersen J: Congenital malformations in newborn infants of diabetic women: correlation with maternal diabetic vascular complications. Lancet 1:1124 (1964).

Pourquié O, Kusumi K: When body segmentation goes wrong. Clin Genet 60:409-416 (2001). 
Quan L, Smith DW: The VATER association. Vertebral defects, anal atresia, radial and renal dysplasia: a spectrum of association defects. J Pediatr 82:104-107 (1973).

Quibell EP: The thalidomide embryopathy: an analysis from the UK. Practitioner 225:721 (1981).

Reardon W, Zhou X-P, Eng C: A novel germline mutation of the PTEN gene in a patient with macrocephaly, ventricular dilatation, and features of VATER association. J Med Genet 38:820-823 (2001)

Reece EA: Diabetes-induced birth defects: what do we know? What can we do? Curr Diab Rep 12:24-32 (2012).

Sadler TW: Langman's Medical Embryology, ed 10 (Lippincott Williams \& Wilkins, Philadelphia 2012).

Sadler TW, Rasmussen SA: Examining the evidence for vascular pathogenesis of selected birth defects. Am J Med Genet A 152A:24262436 (2010).

Shaw EB, Steinbach HL: Aminopterin-induced fetal malformation. Am J Dis Child 115:477 (1968).

Shaw-Smith C: Oesophageal atresia, tracheo-oesophageal fistula, and the VACTERL association: review of genetics and epidemiology. J Med Genet 43:545-554 (2006).
-Shaw-Smith C: Genetic factors in esophageal atresia, tracheo-esophageal fistula and the VACTERL association: Roles for FOXF1 and the 16q24.1 FOX transcription factor gene cluster, and review of the literature. Eur J Med Genet 53:6-13 (2010).

Smith DW: Recognizable Patterns of Human Malformations, ed 3, pp 2, 172, 484 (WB Saunders Company, Philadelphia 1982).

Solomon BD: VACTERL/VATER association. Orphanet J Rare Dis 16:56 (2011).

- Solomon BD, Pineda-Alvarez DE, Raam MS, Bous SM, Keaton AA, et al: Analysis of component findings in 79 patients diagnosed with VACTERL association. Am J Med Genet A 152A:2236-2244 (2010a).

-Solomon BD, Pineda-Alvarez DE, Raam MS, Cummings DAT: Evidence for inheritance in patients with VACTERL association. Hum Genet 127:731-733 (2010b).

-Stevenson RE, Jones KL, Phelan MC, Jones MC Barr M, et al: Vascular steal: the pathogenetic mechanism producing sirenomelia and associated defects of the viscera and soft tissues. Pediatrics 78:451-457 (1986).

Stevenson RE, Kelly JC, Aylsworth AS, Phelan MC: Vascular basis for neural tube defects: a hypothesis. Pediatrics 80:102-106 (1987).
Szumska D, Pieles G, Essalmani R, Bilski M, Mesnard D, et al: VACTERL/caudal regression/Currarino syndrome-like malformations in mice with mutation in the proprotein convertase Pcsk5. Genes Dev 22:14651477 (2008).

Taussig HB: A study of the German outbreak of phocomelia: the thalidomide syndrome. JAMA 180:1106 (1962).

-Varjosalo M, Taipale J: Hedgehog: functions and mechanisms. Genes Dev 22: 2454-2472 (2008).

Ware SM, Peng J, Zhu L, Fernbach S, Colicos S, et al: Identification and functional analysis of ZIC3 mutations in heterotaxy and related congenital heart defects. Am J Hum Genet 74:93-105 (2004).

Weaver DD, Mapstone CL, Yu PL: The VATER association. Analysis of 46 patients. Am J Dis Child 140:225-229 (1986).

-Wessels MW, Kuchinka B, Heydanus R, Smit BJ, Dooijes D, et al: Polyalanine expansion in the ZIC3 gene leading to $\mathrm{X}$-linked heterotaxy with VACTERL association: a new polyalanine disorder? J Med Genet 47:351-355 (2010).

Wiley MJ: The pathogenesis of retinoic acid-induced vertebral abnormalities in golden Syrian hamster fetuses. Teratology 28:341-353 (1983). 